\title{
BLASTOCYSTIS HOMINIS: A MYSTERIOUS AND COMMONLY DISREGARDED PARASITE
}

\author{
Nataša Tasic ${ }^{1,2}$, Tatjana Milenković ${ }^{2}$, Vera Bujic ${ }^{3}$, Dragan Zdravković ${ }^{2}$, Aleksandar Tasić ${ }^{2}$ \\ ${ }^{1}$ University of Niš, Faculty of Medicine, Nišs, Serbia \\ ${ }^{2}$ Public Health Institute, Niš, Serbia \\ ${ }^{3}$ Ministry of Interior, Belgrade, Serbia
}

\begin{abstract}
Blastocystis hominis (B. hominis) is an anaerobic, single-cell protozoan, commonly present in human and animal stool samples. It can be found in healthy people as well and it still has not been elucidated whether it is a commensal organism or a pathogen. Blastocystosis is a disease caused by the protozoan in humans. The prevalence of the parasitosis varies both between the countries, and between certain population groups within individual countries. Due to poor hygienic conditions, common exposure to animals and intake of contaminated water and food, people in the developing countries have got a higher prevalence of blastocystosis, but economically developed countries have not been spared either. The taxonomy of B. hominis is still a matter of debates. For the reasons of genetic diversity, it has been suggested that the name B. hominis should be replaced with „Blastocystis species". Seventeen subtypes of the species have been so far identified, and a definitive characterization of Blastocystis spp. is possible at the molecular level only. The parasite is transferred by the fecal-oral route. A variety of hosts have been identified, and animal-to-human and vice versa transfers have been documented. The most common manifestations of the infection with the organism are diarrhea, abdominal pain, nausea, and bloating. This infection has also been associated with the irritable bowel syndrome (IBS), non-specific colitis, chronic inflammatory bowel disease (CIBD), and urticaria. The diagnosis can be made using the methods of conventional microscopy (CVM), phase-contrast and electron microscopy, cultivation, serodiagnosis, and by using molecular methods. The infection caused by the parasite does not always require treatment. In symptomatic patients, the first line medical treatment is metronidazole. Further studies are required to resolve all dilemmas regarding the parasite.
\end{abstract}

Key words: Blastocystis hominis, diarrheal syndrome, diagnosis, treatment.

\section{Introduction}

Blastocystis hominis (B. hominis) is an ubiquitous parasite spread widely in the tropical climate areas. It is commonly present in human and animal stool specimens (in birds, rodents, reptiles, amphibians, fish, cockroaches). Its role as the cause of an infection has not been fully elucidated. Throughout the literature, the organism has been reported as a commensal organism, but also as a pathogen. In recent years, numerous studies have been published reporting that the infection with $B$. hominis is common in immunocompromised individuals $[1,2]$.

The organism belongs to single cell, anaerobic eukaryotes (protists). Brittain and Swayne, independently of each other, detected the microorganisms studying a cholera epidemic in London in 1849, wrongly identifying them as the cause of cholera [3]. Blastocystis, the name of the genus, was given by Alexeieff in 1911, and the fol-

*Correspondence to: Prof. Nataša Tasić, MD, PhD

Faculty of Medicine, University of Niš,

81 Dr. Zoran Đinđić Blvd, 18000 Niš, Serbia

Phone: +381 184226644

E-mail: nmiltasic@yahoo.com

Received October $27^{\text {th }}, 2016$, accepted for publication January $19^{\text {th }}, 2017$ lowing year the name of the species was suggested by Emile Brumpt [4]. Zierdt et al. performed a reclassification and classified the organism among protists, based on its morphological and phenotypic characteristics (one or several nuclei, cellular organelles similar to mitochondria, endoplasmatic reticulum and Golgi apparatus, inability to grow on fungal culture media, resistance to antifungal agents, and sensitivity to antiprotozoal drugs) [5].

\section{Classification}

At the end of the XX century, Silberman et al. classified the organism among eukaryotes, of the Heterokontophyta type, based on the molecular analyses of small subunit (SSU) rRNA (SSU-rRNA) and elongation factor 1 (EF$1 \alpha$ ) [6]. Although the taxonomy such as this was controversial when related to other studies demonstrating a similarity of Blastocystis spp. parasite with protists, the subsequent studies confirmed the assertion presented above [7, 8]. There are over 100.000 members of the Heterokontophyta order, commonly termed heterokonts or stramenopiles, and Blastocystis spp. becomes a new member of the complex group of the so-called ,botanical protists“ $[9,10]$. By way of phylogenetic analysis of 
SSUrRNA and HSP70c, a close connection between Blastocystis spp. parasite and stramenopiles has been confirmed, in spite of its absence of flagella and tubular elongations [9]. Despite the classification at a molecular level, there is a difference in morphology between blystocystis and other stramenopiles (flagella surrounded by lateral hairlike mastigonemes) $[11,12]$.

The origin of the organism at the species level has not yet been resolved. There are several host-specific species: B. hominis in people, and B. ratti in rats [13]. Host diversity is well known, and human-to-animal and vice versa transfer is well documented [14]. In humans, any of the isolated species is termed B. hominis [4], although, due to its genetic diversity, the suggestions have been put forward that the term $B$. hominis should be replaced with Blastocystis species [13].

Because of all these facts, a step towards classification of different species has been made based on their ultrastructural morphological characteristics visualized by way of electron microscopy [15]. Host specificity and pathogenic potential of different isolates correlate with sequence variations in SSU-rRNA [14]. Conserved and variable regions within 18 SSU-rDNAs constitute the basis for identification of phylogenetic relations between the species [13]. Moreover, rRNAs are made use of in diagnostic PCR analyses with high sensitivity [16]. A recent genetic classification of $B$. hominis into subtypes (STs) is the equivalent to earlier species classification [13]. SSU-rDNAs correlate with subtypes and 17 have been reported so far, so that definitive characterization of species is possible at a molecular level only [13].

Host-specificity is determined by STs, where ST1 and ST8 colonize/infect humans (not only them, however, but other hosts as well) [13]. ST9 has been found only in humans, while ST10-17 are present in other hosts as well $[14,15]$.

\section{Biology and Morphology}

B. hominis is a strict anaerob with observed intacellular structures similar to mitochondria, but lacking cytochrome enzymes. Intracellular organelles are involved in different metabolic pathways (metabolism of amino acids, biogenesis of iron and sulphur, and tricarboxylic acid cycle). The organism is able to synthesize certain essential cellular phospholipids and to accumulate them most commonly within the storage vacuoles [3]. The average generation time of Blastocystis species is $17-22 \mathrm{~h}$, although it depends on the medium used for cultivation. Generation time differs among different STs [17]. The microorganism enters apoptosis after exposure to harsh conditions (exposure to room temperature, air, or antiparasitic agents such as metronidazole). The phenomenon serves as a mechanism aimed to increase the number of viable cells in such conditions [18].

B. hominis has got several different morphological forms. Vacuolar, granular, ameboid, and cystic forms are the ones best described so far. Other morphological forms have also been found on electron microscopy (avacuolar and multivacuolar, of small dimensions and rarely present). In fresh stool samples and culture samples, vacuolar and granular forms are the ones most commonly encountered; they can be visualized using phase-contrast microscopy, with light microscopy of native and stained sample preparations and with electron microscopy [4].

Vacuolar form. This form of B. hominis is spherical, containing a central body representing a large vacuole, occupying approximately $90 \%$ of the cell, and a thin layer of peripheral cytoplasm situated immediately beneath the cell membrane. The nuclei can be distributed peripherally throughout the cytoplasm. There can be seven nuclei at the most, but there are two nuclei on the average, situated at the opposite ends of the cell [19]. Mitochondrion-related organelles and Golgi apparatus are located peripherally in the cytoplasm. Mitochondria look like roses placed around the nucleus. These structures may protrude within the central body and can have a fiberlike appearance [13]. It has been discovered that the central body is a membrane-enclosed vacuole, containing carbohydrates, fats, and basic proteins. These substances are accumulated within the vacuole by way of the action of the Golgi apparatus and via clathrin-mediated endocytosis [20]. The body most probably has storage and apoptosis-related roles [3,9]. Vacuolar forms can be of different sizes (ranging from $3 \mu \mathrm{m}$ to $120 \mu \mathrm{m}$ ), but measuring $5 \mu \mathrm{m}$ to $15 \mu \mathrm{m}$ on the average [13]. It is generally accepted that this form is most commonly seen in asymptomatic carriers of $B$. hominis [1].

Granular form. This form is very similar to vacuolar forms of $B$. hominis, but contains the granules within the cytoplasm which are often centrally situated. In 1989, Dunn et al. proposed that these structures were similar to myelin-like inclusions, small vesicles, crystal granules, and drops of fat. The granules can be metabolic, reproductive, and lipid ones [13]. It is possible that reproductive granules have a role in schizogony. On the average, there are two nuclei in the cytoplasm (four at the most). They have a slightly smaller diameter compared to vacuolar forms, and measure $9.0 \mu \mathrm{m}$ to $28.3 \mu \mathrm{m}$ [19]. They are more frequent in older cultures and the cultures treated with antibiotics, and there has also been the hypothesis that their existence is an indicant of cell death [1].

Ameboid form. This form of $B$. hominis is most rarely encountered. It is irregular in shape, with 1-2 pseudopodia (being stationary nevertheless), with considerable adhesion abilities, enabling its attachment to the bowel mucosa [1]. There is a large vacuole in its cytoplasm, and this form is in fact transformed into cystic form. Since they resemble neutrophils and macrophages, they can easily escape recognition on routine stool sample examinations. Zierdt has suggested Gram staining of unfixed smears to be undertaken for their identification, since these forms undergo lysis when exposed to air, while leukocytes remain intact $[4,9]$. It is more commonly present in individuals with symptoms of digestive tract infections and in cultures, indicating the pathogenic potential of this form of $B$. hominis $[1,21]$. 
Cystic form. These are round or oval, and with smaller dimensions $(3-6 \mu \mathrm{m})$ [13]. These forms found in certain animals are larger [15]. Cystic forms have a thin, multilayered wall with/without a surface envelope [19]. Their condensed cytoplasm has got several mitochondria and storage vacuoles. The number of nuclei within the cysts varies from 1 to 4 . A cyst may survive about a month exposed to air and the temperature of $25^{\circ} \mathrm{C}$ and enables further spread of the infection - it is a form infectious for humans $[1,9]$.

Vegetative forms are transformed into other vegetative forms with different morphology and can thus escape identification in stool samples [3]. Avacuolar and multivacuolar forms are the most dominant forms in vivo, and these also most commonly remain unrecognized on microscopy [22].

\section{Life cycle}

Infectious, cystic forms of $B$. hominis are transmitted by the fecal-oral route [23]. The infection may occur after an intake of untreated water or uncooked water plants contaminated with cysts, and also via dirty hands [24, 25]. In an adequate host, the cyst develops via the process of excitation into vegetative forms within the large bowel [9].

Further continuation of the life cycle depends on the subtype compatibility with the host [13]. Other forms can also develop from vacuolar ones. After a period of time after the infection, vacuolar forms form the cysts in the bowel lumen [22]. The encystation occurs during the passage through the large bowel, and the cysts are then excreted via feces. Fecal cysts can be covered with a fiber-like layer which gradually disappears during the cyst development. A thin fibrillar surface layer detected in stool samples plays a significant role in the survival of this parasite in vivo [22].

It is thought that different modes of reproduction exist when this organism is concerned (binary fission, budding, plasmotomy, multiple fission, endodyogeny, schizogony). Binary fission is nevertheless the most common mode [26].

\section{Virulence}

The studies conducted to establish the pathogenicity of $B$. hominis parasite have been so far unconvincing and disputable. There are some acceptable explanations of pathogenicity related to the species STs and virulence $(27,28)$. Symptomatic patients are usually infected with ST1 - 4, and 6 (with ST3 being the most common, followed by ST1 and ST2). Subtype-related variations in pathogenicity have been observed as well, which probably can explain the differences between the patogenic and non-pathogenic potentials of the species.

Ameboid B. hominis form, which excretes proteases, is the most virulent one. It is predominant in symptomatic patients and these forms should be sought in stool specimens in patient screenings [22,28-30]. In addition to proteases, other hydrolytic enzymes have been identified as well by way of electrophoresis. Lysates lead to cytoskeletal changes and induce apoptosis in epithelial cells, which results in increased bowel permeability. Cystein proteases stimulate mucosal cells to produce interleukin8. This mechanism is responsible for the loss of fluids and bowel inflammation in the affected. Proteases cleave secretory $\operatorname{IgA}$ and help in immune evasion and survival of the parasite [3,31].

Whole-genome sequencing has been done for ST7. The genes have been identified which code the proteins that alter bowel homeostasis. The genes responsible for the production of nonribosomal peptides and polyketides (antibacterial and inducing bowel dysbiosis) have also been identified. The target genes coding for hydrolases have been also described (capable of altering the bowel mucous layer and exposing the epithelium for parasite adhesion). Expression of serine proteases and glycosyltransferases disturbs the firm bonds in the bowel mucose epithelium, leading to increased bowel permeability $[3,32]$.

The molecules responsible for extraintestinal manifestations of the infection are relatively unknown. $B$. hominis antigens stimulate T-helper II cells, leading to an IgE-mediated allergic reaction. The organism probably activates the complement cascade, which leads to the release of anaphylatoxin and mast cell activation. Iron deficiency anemia associated with $B$. hominis infection is still awaiting explanation [33,34]. In general, virulent strains are larger, with an uneven, rough surface, they grow slowly and demonstrate an increased affinity to bind to lectins.

The relationship between the severity of infection and clinical manifestations is still unclear [35-38]. One study has proposed that $32 \mathrm{kDa}$ proteases of ST3 could be the virulent factors responsible for protein degradation, while another study has found that a $B$. hominis $29 \mathrm{kDa}$ antigen could be used as a pathogenicity marker, enabling differentiation of symptomatic from asymptomatic $B$. hominis infections $[39,40]$. Increased IgA levels have been described in symptomatic individuals with $B$. hominis infection, compared to healthy asymptomatic carriers of $B$. hominis [41].

A recent study about the impact of $B$. hominis parasite on the expression of gamma interferon and proinflammatory cytokines of the cecal mucosa in rats has shown a significant upregulated transcription of type 1 gene and proinflammatory cytokines IFN-gamma, IL-12, and TNF- $\alpha$. This suggests that $B$. hominis infection in rats stimulates specific local host responses, involving $\mathrm{T}$ cells, monocytes, macrophages, or natural killer cells [42]. Studies on mice inoculated with high doses of Blastocystis spp. have shown a loss of weight in mice and onset of diarrhea [43-45]. Studies have also demonstrated that Blastocystis spp. can attack the lamina propria, submucose, and muscle layers, and to invade the epithelium of the rat colon in view of the increased levels of hyaluronidase in the urine of rats infected with Blastocystis spp., which stil is not a sufficient proof of similar events in people $[46,47]$. Laboratory rats constitute a good model of the pathogenesis of Blastocystis spp. infection, in con- 
trast to mice which have not been naturally infected with Blastocystis spp. [48].

There have been several reports suggesting that Blastocystis spp. could be associated with urticarias in humans [9]. Ameboid forms of ST3 Blastocystis spp. have been identified in the cases of acute urticaria, and authors believe that cutaneous symptoms can be caused by a disruption in the immune homeostasis [49]. In another study, Blastocystis spp. ST2 has been demonstrated in a patient with severe gastrointestinal complaints and chronic urticaria, in absence of any other infectious agent. The complaints persisted after the initial antibiotic therapy, but were eliminated after combined metronidazole and paromomycin therapy [50].

\section{Clinical Significance and Treatment}

In view of the controversies related to the pathogenicity of $B$. hominis in humans, the results of numerous studies confirmed/excluded $B$. hominis as a disease cause. In certain studies, the individuals susceptible to an infection with the parasite have been mentioned: HIV infected individuals, patients with cancer or with other immune difficiency conditions, children from the developing countries, frequent travellers [13].

It seems that clinical manifestations of blastocystosis depend on the subtype of the parasite. ST1 subtype has been found in those with symptoms of the infection [51], while in Columbia it has been documented in asymptomatic examinees [52]. B. hominis of ST2 has got a controversial pathogenicity, positively demonstrated in some studies [52-54], and disputed in the others [55,56]. Regarding the most common $B$. hominis subtype ST3 isolated in humans, there have been little evidence that could indicate its pathogenicity. Around $40 \%$ of those infected with ST4 of B. hominis have got gastrointestinal symptoms, found as well in those with the clinical picture of severe diarrhea [57,58]; ST5 subtype has been found in those with symptoms of the infection [59], in those coming into contact with animals and in animals themselves $[60,61]$. B. hominis subtype ST6 causes diarrhea in a third of the infected, and B. hominis subtype ST7 is also associated with the onset of diarrhea [57].

Clinical characteristics of the disease are non-specific and consist of abdominal pain, acute/chronic diarrhea, nausea, anorexia, bloating, perianal itching (abdominal pain and diarrhea being the most common complaints). The symptoms range from mild and moderate, to severe acute and chronic events. The number of parasites found in stool specimens determines the severity of symptoms and signs of the infection $[1,9,22,37,38]$.

$B$. hominis is associated with the irritable bowel syndrome (IBS), since the changes in the intestine occur (caused by this disorder) that favor the development of the parasite [13]. It is believed that low-intensity inflammation occurs as the consequence of constant immune activation caused by the parasite and persistent antigen exposure of the host [62]. Moreover, increased levels of IgG2 immunoglobuline against $B$. hominis have been found in the examinees with IBS [63]. Blastocystosis has been associated with non-specific colitis too, as well as with chronic inflammatory bowel disease (HIBD) (including Crohn's disease and ulcerous colitis) [14,64,65].

Eosinophilia and skin changes (primarily urticaria) are rarely encountered in patients $[9,13]$. There have been several individual cases of $B$. hominis infection in patients with chronic kidney disease [66,67] and arthritis $[66,68-71)$. A high prevalence of the infection (95.8\%) has been described in immunocompromised patients (HIV positive individuals and those with AIDS) [72].

However, not all of the infected develop symptoms and signs of the disease. These are asymptomatic individuals there are many more asymptomatic cases than those with symptomatic $B$. hominis infection $[27,30,41,56,64]$.

There is also the question whether the infection with this parasite requires treatment. In symptomatic patients with confirmed infection (the finding of $B$. hominis in the stool specimen), it is necessary to examine the presence of other infective agents in the gastrointestinal tract, since there is a real possibility of coinfection with other pathogens as well [13].

Metronidazole is a first choice drug in cases of proven infection. It's effectiveness, however, has been known to vary. It is effective in some patients, but it cannot produce complete eradication of the infection (especially a severe one). There is a possibility that nonresponders have been infected with resistant $B$. hominis subtypes. The studies dealing with metronidazole efficacy have not elucidated the association between $B$. hominis subtypes and treatment failure [13].

Trimethoprim - sulfamethoxazole is the second choice drug for those who failed to respond to metronidazole treatment. It has been demonstrated that paromomycin, a wide spectrum antibiotic indicated in acute and chronic intestinal amebiasis, is successful as the treatment of Blastocystis infections associated with skin lesions (predominantly urticaria) [73-76].

Yakoob et al. have studied the efficacy of garlic and other dietary herbs in vitro in comparison with metronidazole in individuals infected with $B$. hominis. The authors assessed the efficacy of garlic and metronidazole in concentrations of 0.01 and $0.1 \mathrm{mg} / \mathrm{ml}$. They found that garlic and metronidazole were equally effective in both concentrations. Blastocystis isolates were not sensitive to other tested herbs such as ginger, black pepper, and white cumin [77]. It has been established that probiotics such as Saccharomices boulardii are equally effective as a symptomatic treatment as metronidazole [13,78]. 


\section{Diagnosis}

\section{Conventional microscopy of (CVM) (with/without concentration method):}

- native preparations (unstained/Lugol stained). If Lugol's solution is added, parasites are stained golden yellow. However, due to Blastocystis polymorphic structure, a wrong identification can occur and their misinterpretation as fungi, Cyclospora spp., and drops of fat [13]. Classical vacuolar forms do not have to be predominant in fresh stool sample, while smaller forms can be hard to identify [60]. For the diagnosis of Blastocystis infection to be made, several stool samples (at least 3) are required, more than 5 cysts in the visual field without other parasites [1].

- stained preparations (by Giemsa, Gram, Wright, iron hematoxylin) [80]. A common staining in the diagnosis of Blastocystis is trichrome staining. With this method, the large central body is usually stained green to gray. Inclusion bodies in the cytoplasm stain light to dark red.

\section{Phase-contrast microscopy}

Phase-contrast microscopy is more convenient than light field microscopy when greater magnifications are required and when samples are colorless or their details are so minute that color cannot be discerned well [80]. Phasecontrast microscopy enables the study of morphological features of the cells and of their reproduction via cell division.

The fundamental principle of phase change visualization in phase-contrast microscopy is the separation of background light from the specimen-scattered light, which enables better visualization (highlighting) of the required image details; the phenomenon is based on the property of cells to have a refractive index different than that of the surrounding medium [9].

\section{Transmission electron microscopy (TEM)}

In the routine diagnosis of Blastocystis TEM is not used; it is used however in the demonstration of atypical forms of the parasite [9].

\section{Cultivation}

When CVM specimens are positive to the vacuolar forms of $B$. hominis, cultivation on the LöwensteinJensen (LJ) medium is performed: a 48-hour incubation in anaerobic conditions, when white, very bright and mucous colonies grow [81]. A native preparation with physiological solution is made of the suspect colonies and is inspected microscopically, when vacuolar forms of B. hominis are seen [82].

Xenic and monoxenic laboratory cultures of $B$. hominis isolates, growing together with non-standardized or individual known types of microorganisms, can be kept alive in the Jones' or Boeck-Drbohlav condensed medium $[83,84]$. The Jones' medium is the medium of choice for the studies involving cultures for parasite identification from patient specimens [81,85-88].

Axenic cultures, i.e. the cultures without any other living organism(s), demonstrate a rich growth in different media $[89,90]$. B. hominis cells can grow on a solid medium as well, and its colonies macroscopically appear similar to bacterial colonies [91]. The colonies may survive up to 2 weeks and can be preseeded in a liquid or solid medium [92]. It is interesting that the same isolates cultured in a liquid medium reach their maximum cell density around day 4 after inoculation, and enter the dying phase on day 5, so that the growth of their subcultures is made difficult [9]. This indicates that growth characteristics of the same isolates in a solid medium are essentially different from the characteristics of Blastocystis isolates grown in a liquid medium.

Axenic cultures of Blastocystis isolates are very important for molecular and biochemical research. Axenization can be accomplished by the addition of antibiotic cocktails in order to eliminate bacteria and fungi. Several combinations of antibiotics have been so far described, used with variable success. The procedure is generally a demanding one, lasting for weeks or months, without any guarantee that the bacterial contaminants would be eliminated in the end. It has been supposed that some of the isolates require the presence of bacteria for their survival, so that the removal of all bacteria can result in the death of the parasite [9].

Lanuza et al. have improved the method for Blastocystis spp. axenization and succeeded to axenize 25 out of 81 isolates. The time required for axenization was about 3 weeks [93]. In addition to an antibiotic treatment, some authors have pointed out that physical methods can contribute to the success of axenization - separation of parasites from the mass of sprouting bacteria [93-96].

\section{Serodiagnosis}

The infections caused by B. hominis lead to $\operatorname{IgA}$ and $\mathrm{IgG}$ immune response, and antibodies can be demonstrated using indirect immunofluorescent (IFA) and enzymelinked immunosorbent assay (ELISA) tests [97].

An IFA assay involves a highly specific and sensitive method for the confirmation of $B$. hominis parasite. Commercially available immunofluorescent antibodies are used, specific for B. hominis. Based on polyclonal antibodies, the subtypes of $B$. hominis ST1-ST3 and ST5 can be determined using the ELISA test [97].

Symptomatic infections are associated with elevated IgG antibody titer. In asymptomatic infections, IgA response is weak or absent. The strongest immune response is reported for chronic infections. Since the knowledge concerning host immune response to $B$. hominis infection is still limited, and since antigen diversity of the parasite is obvious, serologic tests are not routinely used, but their use is of key importance in epidemiological and other scientific research. These methods are far more sensitive and specific 
than $\mathrm{CM}$ and the tests are nowadays commercially available $[9,97]$.

\section{Molecular methods}

Amplification of B. hominis DNA obtained from fresh stool samples or from culture is convenient for the purpose of epidemiological and screening studies, and genotyping should be included in the analysis as well [9]. The development of a real time polymerase chain reaction (PCR) method for sufficiently sensitive and rapid detection of Blastocistis spp. and the ability to differentiate between the genotypes present in the specimen would be equally useful in screening and in epidemiological studies [9].

\section{Epidemiology}

B. hominis is a ubiquitous parasite. Its prevalence varies between the countries and from one population group to another. People in the developing countries have got a higher prevalence of blastocystosis due to poor hygienic conditions and intake of contaminated water and food [51].

However, B. hominis has got a wide geographical distribution and can be found in economically developed countries as well $[97,98]$. A study involving the whole territory of the USA, conducted by the Center for Disease Control and Prevention and using the 1987 data, reports the prevalence of $B$. hominis infection of $2.6 \%$ in the general population [99], while a study published in 2000 , performed in private laboratories in 48 states of the USA, shows the prevalence of blastocystosis of $23 \%$ [100]. In Canada, B. hominis was the most common cause of protozoal infections in 2005 (101).

B. hominis was the parasite most commonly isolated in Indonesia, in the HIV infected and those with AIDS tested before the administration of antiretroviral therapy [102] and in Turkey in cancer patients [103]. An increased prevalence of the parasite in individuals in contact with animals suggests the possibility of a zoonosis [27]

The distribution of genotypes established using the PCR method has been reported in several countries: Bangladesh, Germany, Pakistan, Japan, Singapore, Greece, Turkey, China. The ST3 subtype established in China is the most predominant one, while ST1 has been found in a lesser degree in Singapore, Greece, and Germany [13]. There are also mixed type infections with

\section{References}

1. Otašević S, Miladinović Tasić N, Tasić A. Paraziti nejasne taksonomije. In: Otašević S (ed). Medicinska parazitologija (udžbenik sa CD-om). 1st ed. Niš: Medicinski fakultet u Nišu \& Galaksija; 2011. p. 101-105.

2. Stensvold CR, Lewis HC, Hammerum AM et al. "Blastocystis: unravelling potential risk factors and clinical significance of a common but neglected parasite". Epidemiol Infect 2009; 137 (11):1655-63. different subtypes, most commonly with ST1 and ST3 [51,55,104,105].

A recent study in our country has shown that children with blastocystosis have colitis as the most common large bowel pathology, without any significant difference between non-specific colitis and HIBD. The infection is most commonly found in children aged 2 to 3 years, followed by those 16 to 18 years of age. Significantly higher number of the infected live in houses compared to flats, and possess domestic animals and/or pets. A positive fecal occult blood test, iron-deficiency anemia, elevated erythrocyte sedimentation and CRP are characteristic of those with $B$. hominis infection and HIBD who have a larger number of parasites in their stool samples. Mesenteric lymphadenitis and splenomegaly are the most commonly described pathologic changes on the abdominal ultrasound of children infected with $B$. hominis hospitalized for the complaints of abdominal pain and/or diarrhea. The author concludes that the establishment of a pathogenic significance of $B$. hominis contributes to the recognition of this protozoan as a pathogen and stresses the necessity of a treatment for the condition [106].

The first studies in the region of Niš concerning the prevalence of blastocystosis in patients with/without infection symptoms have been published about a decade ago; the prevalence of $4.05 \%$ was then established among the healthy, and $0.36 \%$ among those with symptoms of the infection [107]. Based on still unpublished data of the Parasitology Laboratory, Public Health Institute, the total prevalence of $B$. hominis has been reduced in the last decade $(2.7 \%)$ in asymptomatic individuals.

\section{Conclusion}

Blastocystis hominis is still a mysterious and perhaps scientifically disregarded parasite in human pathology. Differentiation among Blastocystis species is not possible using the routine methods. The use of DNA methods enables detection of genetic variations in these parasites with still uncertain taxonomy. Epidemiological molecular studies are especially useful in the establishment of transmission patterns, host specificity, and in the surveillance of chemotherapeutic resistance.

Distribution and genotypic diversity of Blastocistis spp. have not been studied so far in Serbia, which necessitates a systematic research of the parasite and filling in of the epidemiological map, as well as the establishment of significance of the organism in human pathology.

3. Parija SC, Jeremiah S. Blastocystis: Taxonomy, biology and virulence. Trop Parasitol 2013; 3(1):17-25.

4. Zierdt CH. Blastocystis hominis: Past and future. Clin Microbiol Rev 1991; 4:61-79.

5. Zierdt $\mathrm{CH}$, Rude WS, Bull BS. Protozoan characteristics of Blastocystis hominis. Am J Clin Pathol 1967; 48:495-501.

6. Silberman JD, Sogin ML, Leipe DD, Clark CG. Human parasite finds taxonomic home. Nature 1996; 380:398. 
7. Ho LC, Armiugam A, Jeyaseelan K, Yap EH, Singh M. Blastocystis elongation factor-1alpha: Genomic organization, taxonomy and phylogenetic relationships. Parasitology 2000; 121:135-144.

8. Arisue N, Hashimoto T, Yoshikawa H, Nakamura Y, Nakamura $\mathrm{G}$, Nakamura F et al. Phylogenetic position of Blastocystis hominis and of stramenopiles inferred from multiple molecular sequence data. J Eukaryot Microbiol 2002; 49:42-53.

9. Tan KS. New insights on classification, identification, and clinical relevance of Blastocystis spp. Clin Microbiol Rev 2008; 21:639-665.

10. Riisberg I, Orr RJ, Kluge R, Shalchian-Tabrizi K, Bowers HA, Patil V et al. Seven gene phylogeny of heterokonts. Protist 2009; 160:191-204.

11. Cavalier-Smith, T. A revised six-kingdom system of life. Biol Rev Camb Philos Soc 1998; 73:203-266.

12. Cavalier-Smith T. Sagenista and Bigyra, two phyla of heterotrophic heterokont chromists. Archiv Protist 1997; 148:253-267.

13. Sekar U., Shanthi M. Recent insights into the genetic diversity, epidemiology and clinical relevance of Blastocystis species. J Med Res 2015; 1(1):33-39.

14. Noël C, Dufernez F, Gerbod D, Edgcomb VP, Delgado-Viscogliosi $\mathrm{P}, \mathrm{Ho}$ LC et al. Molecular phylogenies of Blastocystis isolates from different hosts: Implications for genetic diversity, identification of species, and zoonosis. J Clin Microbiol 2005; 43:348-55.

15. Stenzel DJ, Lee MG, Boreham PF. Morphological differences in Blastocystis cysts-an indication of different species? Parasitol Res 1997; 83:452-457.

16. Stensvold CR. Blastocystis: Genetic diversity and molecular methods for diagnosis and epidemiology. Trop Parasitol 2013; 3:26-34.

17. Zierdt $\mathrm{CH}$, Swan JC. Generation time and growth rate of the human intestinal parasite Blastocystis hominis. J Protozool $1981 ; 28: 483-485$

18. Dhurga DB, Suresh KG, Tan TC, Chandramathi S. Apoptosis in Blastocystis spp. is related to subtype. Trans R Soc Trop Med Hyg 2012; 106:725-730.

19. Bergamo do Bomfim TC, Carvalho Machado do Couto M. Morphological diagnosis and occurrence of Blastocystis spp. obtained from the stool samples of domestic bird species commercialized in municipal markets. J Parasitol Vector Biol 2013; 5(3):20-26.

20. Yamada M, Yoshikawa H. Blastocystis: Pathogen or Passenger? In: H. Mehlhorn et al. (eds), Parasitology Research Monographs 4. Berlin, Heidelberg: Springer-Verlag 2012.

21. Vassalos CM, Spanakos G, Vassalou E, Papadopoulou C, Vakalis N. Differences in clinical significance and morphologic features of Blastocystis sp. subtype 3. Am J Clin Pathol 2010; 133:251-258.

22. Vdovenko AA. Blastocystis hominis: Origin and significance of vacuolar and granular forms. Parasitol Res 2000; 86:8-10.

23. Yoshikawa H, Yoshida K, Nakajima A, Yamanari K, Iwatani S, Kimata I. Fecal-oral transmission of the cyst form of Blastocystis hominis in rats. Parasitol Res 2004; 94:391-396.

24. Lee LI, Chye TT, Karmacharya BM, Govind SK. Blastocystis sp.: Waterborne zoonotic organism, a possibility? Parasit Vectors 2012; 5:130.

25. Li LH, Zhou XN, Du ZW, Wang XZ, Wang LB, Jiang JY et al. Molecular epidemiology of human Blastocystis in a village in Yunnan province, China. Parasitol Int 2007; 56:281-286.

26. Zhang X, Qiao JY, Zhou XJ, Yao FR, Wei ZC. Morphology and reproductive mode of Blastocystis hominis in diarrhea and in vitro. Parasitol Res 2007; 101:43-51.

27. Tan KS, Mirza H, Teo JD, Wu B, Macary PA. Current Views on the Clinical Relevance of Blastocystis spp. Curr Infect Dis Rep 2010; 12:28-35.

28. Scanlan PD. Blastocystis: Past pitfalls and future perspectives. Trends Parasitol 2012; 28:327-334.

29. Tan TC, Suresh KG. Predominance of amoeboid forms of Blastocystis hominis in isolates from symptomatic patients. Parasitol Res 2006; 98:189-193.

30. Abdel-Hameed DM, Hassanin OM. Proteaese activity of Blastocystis hominis subtype 3 in symptomatic and asymptomatic patients. Parasitol Res 2011; 109:321-327.
31. Puthia MK, Vaithilingam A, Lu J, Tan KS. Degradation of human secretory immunoglobulin A by Blastocystis. Parasitol Res 2005; 97:386-389.

32. Poirier P, Wawrzyniak I, Vivarès CP, Delbac F, El Alaoui H. New insights into Blastocystis spp.: A potential link with irritable bowel syndrome. PLoS Pathog 2012; 8:e1002545.

33. Valsecchi R, Leghissa $\mathrm{P}$, Greco V. Cutaneous lesions in Blastocystis hominis infection. Acta Derm Venereol 2004; 84: 322-323.

34. Yavasoglu I, Kadikoylu G, Uysal H, Ertug S, Bolaman Z. Is Blastocystis hominis a new etiologic factor or a coincidence in iron deficiency anemia? Eur J Haematol 2008; 81:47-50.

35. Tan TC, Suresh KG, Smith HV. Phenotypic and genotypic characterisation of Blastocystis hominis isolates implicates subtype 3 as a subtype with pathogenic potential. Parasitol Res 2008; 104:85-93.

36. Vassalos CM, Vakalis N, Papadopoulou C. Blastocystis and its pathogenic potential: latest aspects. Rev Med Microbiol 2008, 19:87-97.

37. Boorom KF, Smith H, Nimri L, Viscogliosi E, Spanakos G, Parkar U et al. Oh my aching gut: irritable bowel syndrome, Blastocystis, and asymptomatic infection. Parasit Vectors 2008 $1: 40$.

38. Roberts T, Barratt J, Harkness J, Ellis J, Stark D. Comparison of microscopy, culture, and conventional polymerase chain reaction for detection of Blastocystis sp. in clinical stool samples. Am J Trop Med Hyg 2011; 84(2):308-312.

39. Abdel-Hameed DM, Hassanin OM. Proteaese activity of Blastocystis hominis subtype 3 in symptomatic and asymptomatic patients. Parasitol Res 2011; 109:321-327

40. Abou Gamra MM, Elwakil HS, El Deeb HK, Khalifa KE, Abd Elhafiz HE. The potential use of $29 \mathrm{kDa}$ protein as a marker of pathogenicity and diagnosis of symptomatic infections with Blastocystis hominis. Parasitol Res 2011; 108(5):1139-1146.

41. Mahmoud MS, Saleh WA. Secretory and humoral antibody responses to Blastocystis hominis in symptomatic and asymptomatic human infections. J Egypt Soc Parasitol 2003; 33(1):13-30.

42. Iguchi A, Yoshikawa H, Yamada M, Kimata I, Arizono N Expression of interferon gamma and proinflammatory cytokines in the cecal mucosa of rats experimentally infected with Blastocystis sp. strain RN94-9. Parasitol Res 2009; 105(1):135-140.

43. Moe KT, Singh M, Howe J, Ho LC, Tan SW, Chen XQ et al. Experimental Blastocystis hominis infection in laboratory mice. Parasitol Res 1997; 83(4):319-325.

44. Yao FR, Qiao JY, Zhao Y, Zhang X, Yang JH, Li XQ. Experimental infection of mice with Blastocystis hominis. Zhongguo Ji Sheng Chong Xue Yu Ji Sheng Chong Bing Za Zhi 2005; 23(6):444-448

45. Zhang HW, Li W, Yan QY, He LJ, Su YP. Impact of Blastocystis hominis infection on ultrastructure of intestinal mucosa in mice. Zhongguo Ji Sheng Chong Xue Yu Ji Sheng Chong Bing Za Zhi 2006; 24(3):187-191. (in Chinese)

46. Elwakil HS, Hewedi IH. Pathogenic potential of Blastocystis hominis in laboratory mice. Parasitol Res 2010; 107(3):685-689.

47. Chandramathi S, Suresh KG, Mahmood AA, Kuppusamy UR. Urinary hyaluronidase activity in rats infected with Blastocystis hominis-evidence for invasion? Parasitol Res 2010; 106(6): $1459-1463$.

48. Li J, Deng T, Li X, Cao G, Li X, Yan Y. A rat model to study Blastocytis subtype 1 infections. Parasitol Res 2013; 112(10): 3537-3541

49. Katsarou-Katsari A, Vassalos CM, Tzanetou K, Spanakos G, Papadopoulou C, Vakalis N. Acute urticaria associated with amoeboid forms of Blastocystis sp. subtype 3. Acta Derm Venereol 2008; 88(1):80-81.

50. Vogelberg C, Stensvold CR, Monecke S, Ditzen A, Stopsack K, Heinrich-Grafe U, Pohlmann C. Blastocystis sp. subtype 2 detection during recurrence of gastrointestinal and urticarial symptoms. Parasitol Int 2010; 59(3):469-471.

51. Yan Y, Su S, Lai R, Liao H, Ye J, Li X, et al. Genetic variability of Blastocystis hominis isolates in China. Parasitol Res 2006; 99(5):597-601. 
52. Ramirez JD, Sanchez LV, Bautista DC, Corredor AF, Florez AC, Stensvold CR. Blastocystis subtypes detected in humans and animals from Colombia. Infect Genet Evol 2014; 22: 223-228.

53. Bálint A, Dóczi I, Bereczki L, Gyulai R, Szücs M, Farkas K, et al. Do not forget the stool examination!-cutaneous and gastrointestinal manifestations of Blastocystis $s p$. infection. Parasitol Res 2014; 113(4):1585-1590.

54. Hussein EM, Hussein AM, Eida MM, Atwa MM. Pathophysiological variability of different genotypes of human Blastocystis hominis Egyptian isolates in experimentally infected rats. Parasitol Res 2008; 102(5):853-860.

55. Yoshikawa H, Wu Z, Kimata I, Iseki M, Ali IKMD, Hossain MB, et al. Polymerase chain reaction-based genotype classification among human Blastocystis hominis populations isolated from different countries. Parasitol Res 2004; 92(1):22-29.

56. Dogruman-Al F, Dagci H, Yoshikawa H, Kurt Ö, Demirel M. A possible link between subtype 2 and asymptomatic infections of Blastocystis hominis. Parasitol Res 2008; 103(3):685-589.

57. Roberts T, Stark D, Harkness J, Ellis J. Subtype distribution of Blastocystis isolates identified in a Sydney population and pathogenic potential of Blastocystis. Eur J Clin Microbiol Infect Dis 2013; 32(3):335-343.

58. Stensvold CR, Christiansen DB, Olsen KEP, Nielsen HV. Blastocystis sp. Subtype 4 is Common in Danish BlastocystisPositive Patients Presenting with Acute Diarrhea. Am J Trop Med Hyg 2011; 84(6):883-885.

59. Meloni D, Sanciu G, Poirier P, El Alaoui H, Chabe M, Delhaes L, et al. Molecular subtyping of Blastocystis sp. isolates from symptomatic patients in Italy. Parasitol Res 2011; 109(3):613-619.

60. Stensvold CR, Lewis HC, Hammerum a M, Porsbo LJ, Nielsen SS, Olsen KEP, et al. Blastocystis: unravelling potential risk factors and clinical significance of a common but neglected parasite. Epidemiol Infect 2009; 137(11):1655-1663.

61. Yan Y, Su S, Ye J, Lai X, Lai R, Liao H, et al. Blastocystis sp. subtype 5: a possibly zoonotic genotype. Parasitol Res 2007; 101(6):1527-1532.

62. Stark D, Van Hal S, Marriott D, Ellis J, Harkness J. Irritable bowel syndrome: a review on the role of intestinal protozoa and the importance of their detection and diagnosis. Int $\mathbf{J}$ Parasitol 2007; 37:11-20.

63. Hussain R, Jaferi W, Zuberi S, Baqai R, Abrar N, Ahmed A et al. Significantly increased IgG2 subclass antibody levels to Blastocystis hominisin patients with irritable bowel syndrome. Am J Trop Med Hyg 1997; 56:301-306.

64. Basak S, Rajurkar MN, Mallick SK. Detection of Blastocystis hominis: A controversial human pathogen. Parasitol Res 2014; 113(1):261-265

65. Ozyurt M, Kurt O, Molbak K, Nielsen HV, Haznedaroglu T, Stensvold CR. Molecular epidemiology of Blastocystis infections in Turkey. Parasitol Int 2008; 57(3):300-306.

66. Young CR, Yeo FE. Blastocystis and Schistosomiasis Coinfection in a Patient with Chronic Kidney Disease. Case Rep Med 2014; 2014:1-3.

67. Omrani VF, Fallahi S, Rostami A, Siyadatpanah A, Barzgarpour G, Mehravar S, et al. Prevalence of intestinal parasite infections and associated clinical symptoms among patients with end-stage renal disease undergoing hemodialysis. Infection 2015; 43(5):537-544.

68. Lee MG, Rawlins SC, Didier M, DeCeulaer K. Infective arthritis due to Blastocystis hominis. Ann Rheum Dis 1990; 49(3):192-193.

69. Lakhanpal S, Cohen SB, Fleischmann RM. Reactive arthritis from Blastocystis hominis. Arthritis Rheum 1991; 34(2):251-253.

70. Tejera B, Grados D, Martinez-Morillo M, Roure S. Reactive Arthritis Caused by Blastocistys hominis. Reumatol Clin 2012; 8(1):50-51.

71. Young CR, Yeo FE. Blastocystis and schistosomiasis coinfection in a patient with chronic kidney disease. Case Rep Med 2014; 2014:1-

72. Idris NS, Dwipoerwantoro PG, Kurniawan A, Said M. Intestinal parasitic infection of immunocompromised children with diarrhoea: clinical profile and therapeutic response. $\mathrm{J}$ Infect Dev Ctries 2010; 4(5):309-317.
73. Armentia A, Mendez J, Gomez A, Sanchis E, Fernandez A, de la Fuente R et al. Urticaria by Blastocystis hominis. Successful treatment with paromomycin. Allergol Immunopathol 1993; 21:149-151

74. Kick G, Rueff F, Przybilla B. Palmoplantar pruritus subsiding after Blastocystis hominis eradication. Acta Derm Venereol 2002; 82:60.

75. Pasqui A L, Savini E, Saletti M, Guzzo C, Puccetti L, Auteri A. Chronic urticaria and Blastocystis hominis infection: a case report. Eur Rev Med Pharmacol Sci 2004; 8:117-120.

76. Valsecchi R, Leghissa P, Greco V. Cutaneous lesions in Blastocystis hominis infection. Acta Derm Venereol 2004; 84: 322-323.

77. Yakoob J, Abbas Z, Beg MA, Naz S, Awan S, Hamid S, et al. In vitro sensitivity of Blastocystis hominis to garlic, ginger, white cumin, and black pepper used in diet. Parasitol Res 2011; 109:379-385.

78. Sekar U, Shanthi M. Blastocystis: Consensus of treatment and controversies. Trop Parasitol 2013; 3:35-39.

79. Stenzel DJ, Boreham PF, McDougall R. Ultrastructure of Blastocystis hominis in human stool samples. Int J Parasitol 1991; 21:807-812.

80. Stenzel DJ, Boreham PF. Blastocystis hominis Revisited. Clin Microbiol Rev 1996; 9:563-584

81. Sukthana Y. Is Blastocystis hominis a human pathogenic protozoan? J Trop Med Parasitol 2001; 24:16-22.

82. Basak S, Rajurkar MN, Mallick SK. Detection of Blastocystis hominis: a controversial human pathogen. Parasitol Res 2014; 113(1):261-265

83. Jones, W. R. The experimental infection of rats with Entamoeba histolytica. Ann Trop Med Parasitol 1946; 40:130.

84. Boeck W C, Drbohlav J. The cultivation of Entamoeba histolytica. Am J Hyg 1925; 5:371-407.

85. Leelayoova S, Taamasri P, Rangsin R, Naaglor T, Thathaisong U, Mungthin M. In-vitro cultivation: a sensitive method for detecting Blastocystis hominis. Ann Trop Med Parasitol 2002; 96:803-807.

86. Parkar U, Traub RJ, Kumar S, Mungthin M, Vitali S, Leelayoova S et al. Direct characterization of Blastocystis from faeces by PCR and evidence of zoonotic potential. Parasitology 2007; 134: 359-367.

87. Stensvold CR, Arendrup MC, Jespersgaard C, Mølbak K, Nielsen HV. Detecting Blastocystis using parasitologic and DNA-based methods: a comparative study. Diagn Microbiol Infect Dis 2007; 59:303-307.

88. Stensvold R, Brillowska-Dabrowska A, Nielsen HV, Arendrup MC. Detection of Blastocystis hominis in unpreserved stoo specimens by using polymerase chain reaction. J Parasitol 2006; 92:1081-1087.

89. Ho LC, Singh M, Suresh G, Ng GC, Yap EH. Axenic culture of Blastocystis hominis in Iscove's modified Dulbecco's medium. Parasitol Res 1993; 79:614-616.

90. Zierdt CH, Swan JC, Hosseini J. In vitro response of Blastocystis hominis to antiprotozoal drugs. J Protozool 1983; 30:332-334.

91. Tan KS, Ng GC, Quek E, Howe J, Ramachandran NP, Yap EH et al.. Blastocystis hominis: a simplified, high-efficiency method for clonal growth on solid agar. Exp Parasitol 2000; 96:9-15.

92. Hirata T, Nakamura H, Kinjo N, Hokama A, Kinjo F, Yamane $\mathrm{N}$ et al. Prevalence of Blastocystis hominis and Strongyloides stercoralis infection in Okinawa, Japan. Parasitol Res 2007; 101:1717-1719.

93. Lanuza MD, Carbajal JA, Villar J, Borrás R. Description of an improved method for Blastocystis hominis culture and axenization. Parasitol Res 1997; 83:60-63.

94. Chen XQ, Singh M, Ho LC, Tan SW, Ng GC, Moe KT, et al. Description of a Blastocystis species from Rattus norvegicus Parasitol Res 1997; 83:313-318.

95. Ng GC, Tan KS. Colony growth as a step towards axenization of Blastocystis isolates. Parasitol Res 1999; 85:678-679.

96. Teow WL, Ng GC, Chan PP, Chan YC, Yap EH, Zaman V et al. A survey of Blastocystis in reptiles. Parasitol Res 1992; 78:453-455. 
97. Petersen AM, Stensvold CR, Mirsepasi H, Engberg J, FriisMøller A, Porsbo LJ, et al. Active ulcerative colitis associated with low prevalence of Blastocystis and Dientamoeba fragilis infection. Scand J Gastroenterol 2013; 48(5):638-639.

98. Scanlan PD, Stensvold CR, Rajilić-Stojanović M, Heilig HGHJ, De Vos WM, O'Toole PW, et al. The microbial eukaryote Blastocystis is a prevalent and diverse member of the healthy human gut microbiota. FEMS Microbiol Ecol 2014; 90(1):326-30.

99. Kappus KK, Juranek DD, Roberts JM. Results of testing for intestinal parasites by state diagnostic laboratories, United States, 1987. MMWR CDC Surveill Summ. 1991; 40(4):25-45.

100. Amin OM. Seasonal prevalence of intestinal parasites in the United States during 2000. Am J Trop Med Hyg 2002; 66(6): 799-803.

101. Lagace-Wiens PR, VanCaeseele PG, Koschik C. Dientamoeba fragilis: an emerging role in intestinal disease. Can Med Assoc J 2006; 175(5):468-469.

102. Kurniawan A, Karyadi T, Dwintasari SW, Sari IP, Yunihastuti E, Djauzi S. et al. Intestinal parasitic infections in HIV/AIDS patients presenting with diarrhoea in Jakarta, Indonesia. Trans R Soc Trop Med Hyg 2009; 103:892-898.
103. Tasova Y, Sahin B, Koltas S, Paydas S. Clinical significance and frequency of Blastocystis hominisin Turkish patients with hematological malignancy. Acta Med Okayama 2000; 54: 133-136.

104. Pegelow K, Gross R, Pietrzik K, Lukito W, Richards AL, Fryauff DJ. Parasitological and nutritional situation of school children in the Sukaraja district, West Java, Indonesia. Southeast Asian J Trop Med Public Health 1997; 28:173-190.

105. Wong H, Ng GC, Lin RT, Yoshikawa H, Taylor MB, Tan KS Predominance of subtype 3 among Blastocystis isolates from a major hospital in Singapore. Parasitol Res 2008; 102:663-670.

106. Mirjana Stojšić. The role Blastocistis hominis in the development of colitis in children. PhD Thesis, Medical Faculty, University of Novi Sad, 2016.

107. Tasić S, Miladinović-Tasić N, Zdravković D, Tasić A, Mišić M. Prevalence of infection by Blastocystis hominis parasite, III Macedonian Congress of preventive medicine 2006; (492):136. 